\title{
Frequency of Participation in an Employee Fitness Program and Health Care Expenditures
}

\author{
Jessica Navratil-Strawn, MS, Stephen Hartley, BS, ${ }^{2}$ and Ronald J. Ozminkowski, PhD³
}

\begin{abstract}
Regular physical activity is strongly linked to prevention of costly chronic health conditions. However, there has been limited examination of the impact that level of participation in physical activity promotion programs has on health care costs. This study examined a fitness reimbursement program (FRP) offered to small employers. FRP participants received $\$ 20$ reimbursement every month they visited their fitness center $\geq 12$ days. Visits were recorded electronically. Participants were assigned to 4 mutually exclusive cohorts by mean monthly fitness center visits: low ( $<4$ visits); low-moderate ( $\geq 4$ and $<8$ visits), high-moderate ( $\geq 8$ and $<12$ visits), and high $(\geq 12$ visits, which qualified for reimbursement). Cohorts were matched by inverse propensity score weighting on demographic, health status, health care supply, and socioeconomic characteristics. Between-cohort differences in propensity score-weighted health care costs, starting from FRP program sign-up, were examined with a generalized linear model. Analyses were conducted with and without high-cost outliers during the pre- and post-FRP period. A total of 8723 participants (mean follow-up: 11.1 months) were identified during October 2010-June 2013. With high-cost outliers removed $(n=226)$, a pattern of lower per-member-per-month health care costs was observed with increasing participation: compared with the low cohort, monthly savings were: $\$ 6.14(2.6 \%)$ for low-moderate $(P=0.60), \$ 16.40(6.9 \%)$ for moderate-high $(P=0.16)$, and $\$ 20.01(8.4 \%)$ for high $(P=0.08)$. With high-cost outliers included, significant monthly cost savings were observed for the moderate-high $(\$ 43.52$, $P<0.01)$ and high $(\$ 52.66, P<0.001)$ cohorts. These results indicate directionally positive cost outcomes associated with increasing level of fitness center participation.
\end{abstract}

\section{Introduction}

$\mathbf{T}$ HE BENEFITS OF REGULAR PHYSICAL activity for preventing adverse health outcomes are well established. ${ }^{1}$ Adults who regularly engage in moderate or more vigorous physical activity have a reduced risk of several common diseases including coronary heart disease, ${ }^{2}$ type 2 diabetes, ${ }^{3}$ stroke, ${ }^{4}$ breast cancer, ${ }^{5}$ and colon cancer. ${ }^{6}$ The 2008 Physical Activity Guidelines for Americans recommend at least 150 minutes per week of moderate intensity activity, 75 minutes of vigorous activity, or an equivalent combination of both. ${ }^{7}$ Muscle-strengthening activities on 2 or more days/week also are recommended. ${ }^{7}$ Yet, in 2011 , only $56 \%$ of privately insured Americans aged 18-64 years met the guidelines for leisure time aerobic activity and only $26 \%$ met the guidelines for both aerobic activity and muscle strengthening. ${ }^{8}$ In the United States, a sedentary lifestyle was ranked as the $5^{\text {th }}$ highest risk factor for death ${ }^{9}$ and the medical costs attributable to physical inactivity have been estimated at $\$ 75 \mathrm{~B}$ annually. ${ }^{10}$
Employers have a vested interest in their employees' health to improve productivity and control rising health care costs. In 2014, $74 \%$ of US employers who provided health insurance to their employees also offered at least 1 health and wellness program. ${ }^{11}$ Programs aimed at encouraging physical activity, such as gym membership discounts or onsite exercise facilities, are a common component of health and wellness programs. ${ }^{11}$ Health care savings have been reported for several employer health and wellness programs $^{12-15}$ and a rigorous meta-analysis found savings of $\$ 3.27$ in medical costs per program dollar spent. ${ }^{16}$ However, these studies are based largely on multifaceted programs with a comprehensive range of offerings (eg, disease management, health risk screening, healthy lifestyle promotion) and thus lack the ability to assess which specific components of the program are the most cost-effective. Some analyses of comprehensive health and wellness programs indicate that return on investment is driven primarily by a single component such as disease management. ${ }^{17,18}$

\footnotetext{
${ }^{1}$ Optum, Minneapolis, Minnesota.

${ }^{2}$ Optum, Phoenix, Arizona.

${ }^{3}$ Optum, Ann Arbor, Michigan.
} 
There has been limited study of the impact of employersponsored physical activity programs on health care costs with a specific focus on the association between level of physical activity participation and health care savings. ${ }^{19,20}$ In a study of a single large employer program that provided an incentive-based initiative for frequent fitness center visits, program participants who visited fitness centers more often had lower health care costs compared with nonparticipants. ${ }^{20}$ The present study sought to extend these findings by examining a similar program among members of a large national health plan. The objective was to examine the relationship between the number of monthly fitness center visits and health care costs among participants in a program that offered an economic incentive for more frequent fitness center visits. The return on investment for the incentive feature also is reported. This study expands on prior research by focusing on program participants only. To minimize the likelihood of selection bias, the study population was limited to health plan members who agreed to participate in the program, with the lowest participation cohort serving as the comparator group, rather than nonparticipants. Fixed and random effects modeling procedures were used, which are designed to help avoid selection bias related to unmeasurable factors that might influence program participation and outcomes.

\section{Methods}

\section{Intervention}

In October 2010, a large national health plan began offering the Fitness Reimbursement Program (FRP) to small business employers (2-99 employees). Health plan members who enrolled in FRP selected a fitness center from partici- pating facilities eligible for reimbursement within their respective area. At each fitness center visit, FRP participants swiped a card or key fob that recorded each visit; each visit earned 1 credit up to a maximum of 1 credit per day. FRP participants who visited a fitness center 12 or more times in any given month were reimbursed $\$ 20$ for each month when utilization was that high. Reimbursements were credited at the end of each month in which reimbursement was earned, or at the beginning of the following month.

\section{Design and data source}

This was retrospective cohort study with data collected during April 1, 2010, through December 31, 2013. Member characteristics and health care claims were captured from an administrative claims database affiliated with Optum. Claims data included medical (facility and professional) and pharmacy claims with both health plan and patient paid amounts.

\section{Member selection and cohort definition}

An index date for each sample member was defined as the date the member enrolled in FRP during the participant identification period (October 1, 2010, through June 30, 2013) (Table 1). Inclusion in the study required continuous medical coverage in the health plan for at least 6 months pre index (starting as early as April 1, 2010, for participants who enrolled in the FRP on October 1, 2010) and at least 6 months post index (ending as late as December 31, 2013, for those who enrolled on June 30, 2013). Medical cost differentials between study cohorts were assessed using data from 6 to 12 months after the FRP began, with 3 additional months of claims run out that were examined to account for

Table 1. Selection of Study Sample

\begin{tabular}{|c|c|c|c|c|c|}
\hline & \multicolumn{4}{|c|}{$\begin{array}{c}\text { Level of Fitness Reimbursement } \\
\text { Program Participation }^{\mathrm{a}}\end{array}$} & \multirow[b]{2}{*}{$\begin{array}{l}\text { Total } \\
\mathrm{n}(\%)\end{array}$} \\
\hline & $\begin{array}{l}L^{L} w^{\mathrm{a}} \\
\mathrm{n}(\%)\end{array}$ & $\begin{array}{l}\text { Low- } \\
\text { Moderate } \\
\mathrm{n}(\%)\end{array}$ & $\begin{array}{l}\text { High- } \\
\text { Moderate } \\
\mathrm{n}(\%)\end{array}$ & $\begin{array}{l}H_{\text {igh }}^{\mathrm{a}} \\
\mathrm{n}(\%)\end{array}$ & \\
\hline $\begin{array}{l}\text { Starting sample: health plan members with } \\
\text { continuous medical coverage } \\
\text { April 1, 2010-December } 31,2013\end{array}$ & 7227 & 5414 & 5131 & 5331 & $23,103(100)$ \\
\hline Exclusion criterion & & & & & Exclusions, n (\%) \\
\hline $\begin{array}{l}\text { FRP enrollment (Index) date } \\
\text { after June } 30,2013\end{array}$ & 1497 & 1146 & 1130 & 1245 & $5018(21.7)$ \\
\hline $\begin{array}{l}<6 \text { months continuous enrollment } \\
\text { pre index and/or post index }\end{array}$ & 1954 & 1466 & 1338 & 1366 & $6124(26.5)$ \\
\hline $\begin{array}{l}\text { Not an active employee aged } \\
18-64 \text { years as of index date }\end{array}$ & 704 & 528 & 574 & 584 & $2390(10.3)$ \\
\hline $\begin{array}{l}\text { Maternity-related or complex } \\
\text { medical condition }{ }^{\mathrm{b}}\end{array}$ & 47 & 22 & 12 & 24 & $105(0.5)$ \\
\hline Missing and propensity score variable & 173 & 104 & 110 & 130 & $517(2.2)$ \\
\hline High-cost outlier ${ }^{\mathrm{c}}$ & 73 & 48 & 53 & 52 & $226(1.0)$ \\
\hline Final study sample & $2779(38.5)$ & $2100(38.8)$ & $1914(37.3)$ & $1930(36.2)$ & $8723(37.8)$ \\
\hline
\end{tabular}

${ }^{a}$ Participation cohorts defined according to number of PMPM fitness center visits during post-index period: low, $<4$; low-moderate, $\geq 4$ and $<8$; high-moderate, $\geq 8$ and $<12$; high, $\geq 12$.

${ }^{b}$ Maternity-related claim or other pregnancy-related condition during the pre- or post-index period; complex medical condition, diagnostic or procedure claims for any of the following during the study period: cancer, end stage renal disease, HIV/AIDS, organ transplant, trauma, or mental disorder.

${ }^{\mathrm{c}}$ High-cost outlier defined as monthly total health care costs greater than the $97.5^{\text {th }}$ percentile of the study sample.

$\mathrm{FRP}=$ fitness reimbursement program; $\mathrm{PMPM}=$ per member per month. 
any delay in claims processing (eg, if a member's FRP enrollment date was June 30, 2013, then claims reflecting his or her health care service dates from June 30, 2013, to December 31, 2013, were used in the analysis). Claims that were paid through March 31, 2014, were reviewed to allow for the 3 months of run out needed to make sure all services used in the few months of 2013 could be accounted for in the analysis, because sometimes it takes a few months for all claims to be paid after services are incurred.

FRP participants were excluded from the study if they were not active employees aged 18-64 years as of the index date (ie, retirees younger than age 65, spouses and dependents of active employees), if they had a maternity-related claim or other pregnancy-related condition during the preor post-index period; or if they had any medical claim containing a diagnosis or procedure code for cancer, HIV/ AIDS, organ transplant, trauma, or mental disorder during the pre- or post-index period.

FRP participants were assigned to 4 mutually exclusive cohorts according their average level of FRP participation, defined as the mean number of monthly visits to a fitness center during the post-index or follow-up period. FRP cohorts were labeled as describing: low participation $(<4$ visits per month on average); low-moderate participation ( $\geq 4$ and $<8$ visits per month on average), high-moderate participation ( $\geq 8$ and $<12$ visits per month on average), and high participation ( $\geq 12$ visits per month on average). Members in any cohort received the $\$ 20$ incentive for any month in which their utilization met or exceeded 12 visits, but cohort assignment was based on their average utilization.

\section{Measures}

Demographic, health status, health care supply, and socioeconomic characteristics of FRP participants were collected to account for factors other than the amount of FRP participation that also influence health care costs. Demographic characteristics were: age as of the index date, sex, US census region of residence, and a binary variable (yes/no) indicating residence in a metropolitan statistical area. Health status during the 6-month pre-index period was assessed by count of inpatient stays, count of emergency room visits, total health care costs, and Charlson comorbidity score. ${ }^{21}$ Indices of health care supply that have been shown to influence health care expenditures $^{22}$ were determined according to the member's zip code of residence. These included the number of primary care providers per 100,000 residents, number of medical specialists per 100,000 residents, and number of hospital beds per 1000 residents. Socioeconomic characteristics were determined at the zip code level using the 2010 US Census as the reference: these included minority ratio, categorized as high, medium, or low according to the percentage of minority residents, and income level grouped as high ( $1^{\text {st }}$ quartile), medium-high $\left(2^{\text {nd }}\right.$ quartile), medium-low ( $3^{\text {rd }}$ quartile), and low ( $4^{\text {th }}$ quartile). Other characteristics included the season of the index month and a binary indicator of continuous pharmacy benefits during both 6-month preindex and post-index periods. A retrospective risk score derived from 12-month pre-index health care costs, centered around 1.0, was used to predict whether allowed charges for the member were expected to be higher or lower than the population's average for the following year.
The outcome was total health care costs during follow-up, starting from the month of the index date and continuing for at least 6 and up to 12 months post index. Because of variable length of follow-up, costs were determined on a per-member-per-month (PMPM) basis. Total costs were calculated as the sum of all medical and pharmacy costs, including both health plan and member paid amounts.

\section{Statistical analysis}

Inverse propensity score weighting ${ }^{23,24}$ was used to minimize differences in demographics, health status, health care supply, and socioeconomic characteristics among the 4 cohorts of FRP participants. To apply the weighting technique, one must first generate a propensity score for each sample member. The propensity score was derived by logistic regression modeling, using the FRP participant's demographic, health status (including pre-index health care costs), and other characteristics that were already defined as adjustment variables. The propensity score for each member was obtained from the logistic regression output as his or her predicted probability of being in the FRP participant cohort that he or she actually was in. The propensity score for each member was then transformed into a case weight for subsequent regression analysis; the weight was defined as 1.0 divided by the member's propensity score value.

To estimate the impact of FRP participation on health care expenditures in a way that would help avoid selection bias, propensity score weighted health care costs during follow-up were modeled with a fixed effects generalized linear model (GLM), with a gamma distribution and log-link. The GLM model included the FRP cohort as the primary independent variable and participant characteristics as adjustment variables. Multicolinearity of adjustment variables was assessed by reviewing the variance inflation factor and condition index values for each variable. Variables with a variance inflation factor $\geq 10$ or condition index $\geq 30$ were removed from the regression models. High-cost outliers, defined as FRP participants with follow-up monthly total health care costs greater than the $97.5^{\text {th }}$ percentile of the study sample, were removed from the primary analysis as well. Two sets of sensitivity analyses also were conducted for total health care costs. The first sensitivity analysis was the same as the primary analysis except that high-cost outliers were retained. The second set of sensitivity analyses employed a random effects, rather than fixed effects, GLM, with and without outliers excluded.

\section{Return on investment (ROI) analyses}

PMPM health care cost results were used to estimate the financial ROI associated with the FPR incentive feature. Differences in health care expenditures between higher users and the low user group were estimated via the regression modeling described. These differences were then contrasted with the cost of the incentive feature to estimate savings PMPM, and the associated ROI ratio (ie, savings divided by incentive costs).

\section{Results}

\section{Member sample and characteristics}

The initial sample members included 23,103 health plan members who enrolled in the FRP during October 1, 2010, 
Table 2. Pre and Post Propensity Score-Weighted FrP Participant Characteristics

\begin{tabular}{|c|c|c|c|c|c|c|c|}
\hline \multirow[b]{4}{*}{ Propensity score weighting variables ${ }^{\mathrm{c}}$} & \multicolumn{7}{|c|}{ Level of Fitness Reimbursement Program Participation $t$} \\
\hline & \multicolumn{2}{|r|}{$L^{\prime a} w^{\mathrm{a}}$} & \multicolumn{2}{|c|}{ Low-Moderate ${ }^{\mathrm{a}}$} & \multicolumn{2}{|c|}{ High-Moderate } & \multirow{2}{*}{$\begin{array}{c}H_{i g h}^{\mathrm{a}, \mathrm{b}} \\
\mathrm{n}=1930\end{array}$} \\
\hline & \multicolumn{2}{|r|}{$\mathrm{n}=2779$} & \multicolumn{2}{|r|}{$\mathrm{n}=2100$} & \multicolumn{2}{|r|}{$\mathrm{n}=1914$} & \\
\hline & $\%$ & STD Difference ${ }^{\mathrm{c}}$ & $\%$ & STD Difference ${ }^{\mathrm{c}}$ & $\%$ & STD Difference ${ }^{\mathrm{c}}$ & $\%$ \\
\hline \multicolumn{8}{|l|}{ Pre-Propensity Score Weighting } \\
\hline $31-39$ & 29.18 & 0.308 & 27.28 & 0.259 & 21.39 & 0.055 & 20.20 \\
\hline $40-49$ & 24.23 & 0.122 & 24.81 & 0.096 & 25.93 & 0.049 & 27.19 \\
\hline$\geq 50$ & 18.85 & 0.964 & 22.48 & 0.647 & 30.91 & 0.198 & 37.03 \\
\hline Female, \% & 54.55 & 0.253 & 50.29 & 0.190 & 48.00 & 0.151 & 40.74 \\
\hline \multicolumn{8}{|l|}{ Season of index month } \\
\hline Spring & 30.72 & 0.140 & 28.80 & 0.083 & 26.86 & 0.016 & 26.42 \\
\hline Summer & 20.32 & 0.082 & 18.80 & 0.170 & 21.44 & 0.026 & 21.99 \\
\hline Fall & 14.14 & 0.197 & 14.49 & 0.168 & 16.02 & 0.057 & 16.92 \\
\hline Metropolitan statistical area & 91.58 & 0.008 & 92.60 & 0.018 & 91.36 & 0.005 & 90.89 \\
\hline \multicolumn{8}{|l|}{ Census region } \\
\hline Midwest & 37.20 & 0.065 & 40.11 & 0.012 & 40.77 & 0.028 & 39.63 \\
\hline \multicolumn{8}{|l|}{ Income level $^{\mathrm{d}}$} \\
\hline Low & 4.11 & 0.273 & 3.86 & 0.225 & 3.91 & 0.235 & 2.99 \\
\hline Lower middle & 9.29 & 0.232 & 9.78 & 0.270 & 7.52 & 0.051 & 7.14 \\
\hline Upper middle & 24.83 & 0.136 & 21.94 & 0.022 & 22.95 & 0.065 & 21.46 \\
\hline \multicolumn{8}{|l|}{ Minority ratio ${ }^{\mathrm{d}}$} \\
\hline Low & 60.48 & 0.113 & 62.10 & 0.084 & 66.40 & 0.014 & 67.31 \\
\hline Medium & 35.55 & 0.153 & 34.59 & 0.129 & 29.89 & 0.008 & 30.12 \\
\hline \multirow{2}{*}{ High } & 3.96 & 0.351 & 3.31 & 0.222 & 3.71 & 0.307 & 2.57 \\
\hline & mean & STD Diff & mean & STD Diff & mean & STD Diff & mean \\
\hline 6-month pre-index ER visit count & 0.07 & 0.008 & 0.05 & 0.003 & 0.05 & 0.005 & 0.06 \\
\hline $\begin{array}{l}\text { 6-month pre-index inpatient } \\
\text { admission count }\end{array}$ & 0.02 & 0.003 & 0.01 & 0.000 & 0.01 & 0.002 & 0.01 \\
\hline Retrospective risk score ${ }^{\mathrm{e}}$ & 1.15 & 0.006 & 1.03 & 0.016 & 1.05 & 0.013 & 1.12 \\
\hline $\begin{array}{l}\text { Pre-index Charlson comorbidity } \\
\text { index score, }\end{array}$ & 0.18 & 0.003 & 0.17 & 0.007 & 0.19 & 0.001 & 0.19 \\
\hline \multicolumn{8}{|l|}{ Post-Propensity Score Weighting } \\
\hline \multicolumn{8}{|l|}{ Age category, years } \\
\hline $31-39$ & 24.96 & 0.002 & 24.74 & 0.007 & 25.03 & 0.005 & 24.92 \\
\hline $40-49$ & 25.20 & 0.005 & 25.26 & 0.003 & 25.15 & 0.007 & 25.33 \\
\hline$\geq 50$ & 26.50 & 0.005 & 26.72 & 0.003 & 26.59 & 0.002 & 26.63 \\
\hline Female, \% & 49.23 & 0.007 & 48.77 & 0.002 & 49.18 & 0.006 & 48.87 \\
\hline \multicolumn{8}{|l|}{ Season of index month } \\
\hline Spring & 28.78 & 0.025 & 28.31 & 0.009 & 28.57 & 0.018 & 28.06 \\
\hline Summer & 20.54 & 0.009 & 20.69 & 0.016 & 20.88 & 0.025 & 20.36 \\
\hline Fall & 15.04 & 0.006 & 15.35 & 0.014 & 15.17 & 0.003 & 15.13 \\
\hline Metropolitan statistical area & 91.93 & 0.002 & 92.16 & 0.005 & 92.14 & 0.004 & 91.73 \\
\hline Census region & & & & & & & \\
\hline Midwest & 41.26 & 0.004 & 40.98 & 0.003 & 41.00 & 0.003 & 41.11 \\
\hline Income level $^{\mathrm{d}}$ & & & & & & & \\
\hline Low & 3.90 & 0.011 & 3.96 & 0.027 & 3.94 & 0.021 & 3.86 \\
\hline Lower middle & 9.03 & 0.017 & 8.94 & 0.027 & 8.91 & 0.031 & 9.19 \\
\hline Upper middle & 24.51 & 0.017 & 23.78 & 0.014 & 24.09 & 0.001 & 24.10 \\
\hline Minority ratio ${ }^{d}$ & & & & & & & \\
\hline Low & 63.84 & 0.002 & 63.38 & 0.006 & 63.38 & 0.006 & 63.74 \\
\hline Medium & 32.69 & 0.005 & 33.18 & 0.010 & 33.10 & 0.008 & 32.84 \\
\hline High & 3.47 & 0.016 & 3.44 & 0.005 & 3.52 & 0.028 & 3.42 \\
\hline & mean & STD Diff & mean & STD Diff & mean & STD Diff & mean \\
\hline 6-month pre-index ER visit count & 0.06 & 0.002 & 0.06 & 0.004 & 0.06 & 0.001 & 0.05 \\
\hline $\begin{array}{l}\text { 6-month pre-index inpatient } \\
\text { admission count }\end{array}$ & 0.01 & 0.001 & 0.02 & 0.002 & 0.01 & 0.001 & 0.01 \\
\hline Retrospective risk score & 1.08 & 0.002 & 1.10 & 0.005 & 1.08 & 0.001 & 1.07 \\
\hline $\begin{array}{l}\text { Pre-index Charlson comorbidity } \\
\text { index score }\end{array}$ & 0.19 & 0.000 & 0.19 & 0.001 & 0.18 & 0.001 & 0.19 \\
\hline
\end{tabular}

${ }^{\text {a }}$ Participation cohorts defined according to number of PMPM fitness center visits during post-index period: low, $<4$; low-moderate, $\geq 4$ and $<8$; high-moderate, $\geq 8$ and, $<12$; high, $\geq 12$.

${ }^{b}$ High participation cohort is the reference group for standardized differences.

${ }^{\mathrm{c}}$ Standardized difference value $\geq 0.1$ indicates significant difference (bolded values).

${ }^{\mathrm{d}}$ Based on member zip code of residence; income categories are quartiles based on median income in the member's zip code according to 2010 US Census.

${ }^{\mathrm{e}}$ Derived from 12-month pre-index health care costs to predict whether allowed charges would be higher than an average for the following year.

$\mathrm{ER}=$ emergency room; FRP = fitness reimbursement program; $\mathrm{PMPM}=$ per member per month; $\mathrm{STD}=$ standardized. 
through December 31, 2013, (Table 1). After applying exclusion criteria and removing high-cost outliers, 8723 participants (37.8\% of initial study sample) were retained. The percentage of participants retained was similar across FRP cohorts. The primary reasons for exclusion were lack of continuous health plan enrollment with medical benefits during both the 6-month pre-index and 6-month post-index period (26.5\% excluded) and FRP enrollment date occurring after June 30, 2013 (21.7\% excluded).

High-cost outliers were determined as the highest cost $2.5 \%$ of the final study population. The percent of outliers was similar in each of the 4 groups with $2.6 \%$ in the low user group, $2.2 \%$ in the low-moderate group, $2.7 \%$ in highmoderate group, and $2.6 \%$ among high users. Outliers averaged 370 annual emergency room visits per 1000 and 337 annual inpatient admissions per 1000 while the non-outliers had 102 annual emergency room visits per 1000 and 15 annual inpatient visits per 1000 (data not shown). All differences between outliers and non-outliers were statistically significant $(P<0.0001$. $)$

The propensity score variables and FRP participant characteristics before and after propensity score weighting are shown in Table 2. Prior to propensity score weighting, large differences among cohorts were evident for age group, season of index month, and socioeconomic markers; this is evidenced by standardized difference values for these variables that were greater than 0.10 . After propensity score weighting, participant characteristics were rendered similar across FRP cohorts (ie, all standardized difference values were less than 0.10).

\section{Length of follow-up and fitness center visits}

On average, participants were followed for 11 months after FRP enrollment (Table 3). The mean PMPM fitness center visits for each cohort ranged from 1.7 for the low participant cohort to 15.3 for the high participant cohort. In the low participation cohort, $2.29 \%$ of participants had 0 PMPM visits.

\section{Total health care costs}

Propensity score-weighted total health care costs during follow-up are shown in Table 4 . In the primary analysis using a fixed effects model with high-cost outliers removed, a trend for lower health care costs with increasing level of FRP participation was evident. Compared with the low participation cohort, PMPM total health care costs were lower by $2.6 \%$ in the low-moderate cohort $(P=0.60), 6.9 \%$ in the high moderate cohort $(P=0.16)$, and $8.4 \%$ in the high participation cohort $(P=0.08)$. In the sensitivity analysis with high-cost outliers included, the same trend for declining PMPM health care costs was apparent at the moderate-high and high participation levels, and the difference compared with the low participation cohort was statistically significant for the high participation cohort $(P<0.001)$. In the sensitivity analysis using a random effects model, lower PMPM costs also were observed at higher levels of participation: with outliers excluded, total PMPM costs were lower compared with the low participation cohort for low-moderate $(P=0.752)$, moderatehigh $(P=0.791)$, and high $(P=0.132)$ participation cohorts. When outliers were included in the random effects model, total PMPM costs were higher for low-moderate $(P=0.919)$, lower for high-moderate $(P=0.129)$ and lower for high $(P=0.011)$ participation cohorts.

\section{$\mathrm{ROI}$ analyses}

Table 5 shows the results of the return on investment (ROI) analyses on the sample that excluded the high-cost outliers $(\mathrm{n}=8723)$. This is the sample that yielded lower savings, so ROI results reported here may be conservative. Group membership in this study was based on the average number of fitness facility visits per month, but there were a few members who had individual months with 12 or more visits in each group, and they received the $\$ 20$ incentive for each of those months. Thus, some incentive dollars were paid to members of each user group (see row A in Table 5). The average monthly incentive payments varied from $\$ 0.35$ for the low user group to $\$ 17.28$ for the high user group (row B). Savings in health care for members of each group are shown in comparison to the low user group (row $\mathrm{C}$ ). The overall average health care savings was \$9.50 PMPM.

Net savings per group also are reported in Table 5. Net savings are defined as the difference in health care savings vs. the cost of the incentive. For the entire study sample (excluding outliers) the average net savings was \$2.76 PMPM.

Finally, ROI ratios for each group are reported in Table 5. The ROI for the entire study sample was estimated to be a savings of $\$ 1.41$ in health care expenditures per dollar spent on the incentive.

\section{Discussion}

The results of this study suggest a trend for lower health care costs with increasing level of FRP participation. Compared with lowest level of participation, when a small

Table 3. Duration of Follow-up and Number of Fitness Center Visits

\begin{tabular}{lcccc}
\hline & \multicolumn{3}{c}{ Level of Fitness Reimbursement Program Participation } \\
\cline { 2 - 5 } & $\begin{array}{c}\text { Low }^{\mathrm{a}} \\
\mathrm{n}=2779)\end{array}$ & $\begin{array}{c}\text { Low-Moderate }^{\mathrm{a}} \\
(\mathrm{n}=2100)\end{array}$ & $\begin{array}{c}\text { High-Moderate }^{\mathrm{a}} \\
(\mathrm{n}=1914)\end{array}$ & $\begin{array}{c}\text { High }^{\mathrm{a}} \\
(\mathrm{n}=1930)\end{array}$ \\
\cline { 2 - 5 } & Mean $(S D)$ & Mean $(S D)$ & Mean $(S D)$ & Mean $(S D)$ \\
\hline Follow-up (post-index) period, months & $11.2(1.7)$ & $11.2(1.7)$ & $11.3(1.6)$ & $11.2(1.7)$ \\
Number of fitness center visits, PMPM & $1.7(1.2)^{\mathrm{b}}$ & $5.9(1.2)$ & $10.0(1.1)$ & $15.3(3.1)$ \\
\hline
\end{tabular}

${ }^{a}$ Participation cohorts defined according to number of PMPM fitness center visits during post-index period: low, $<4$; low-moderate, $\geq 4$ and $<8$; high-moderate, $\geq 8$ and, $<12$; high, $\geq 12$.

$\mathrm{b}_{2.29 \%}$ had 0 PMPM visits.

$\mathrm{PMPM}=$ per member per month; $\mathrm{SD}=$ standard deviation. 


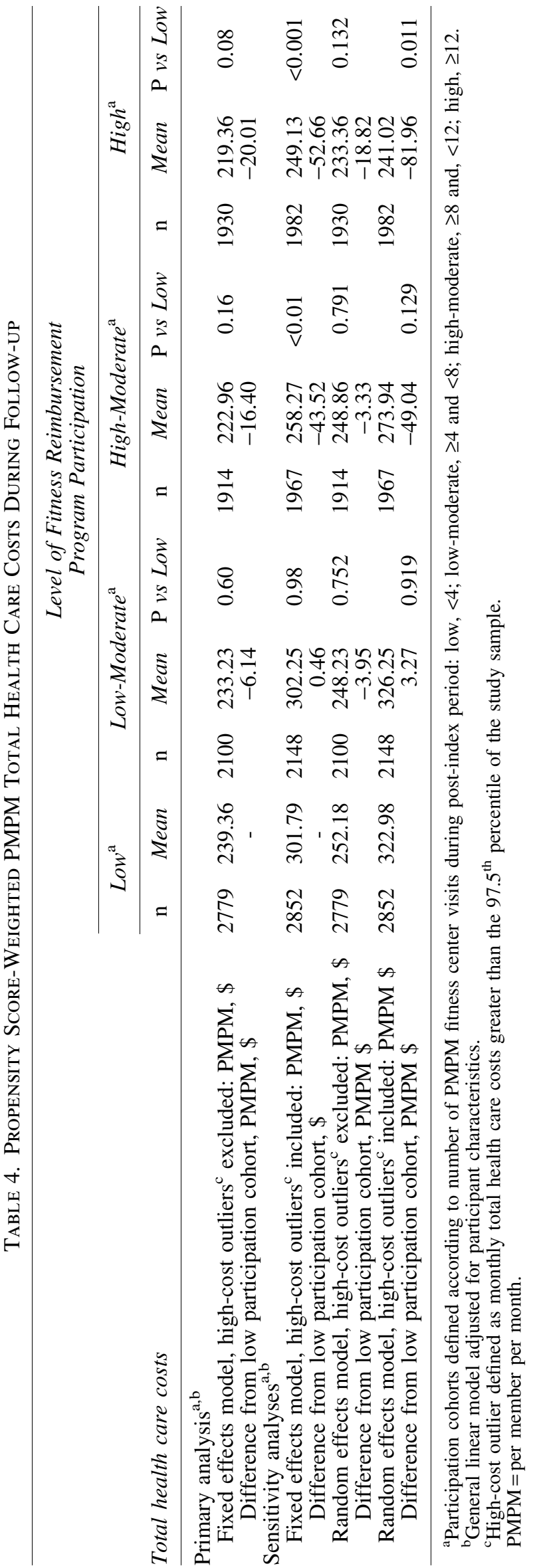

number of high-cost outliers were removed from the sample, monthly health care savings ranged from $\$ 6.14$ (2.6\%) per member at the low-moderate level of participation to $\$ 20.01$ $(8.4 \%)$ per member at the highest level of participation. Although differences were not statistically significant at the conventional alpha $\leq 0.05$ threshold, the difference in health care costs between the lowest and highest level of participation approached significance $(P=0.08)$ for the high users.

From a statistical perspective, $P$ values higher than 0.05 do not imply that $\$ 0$ savings would be a better estimate for any group of members. The best estimates are still the values reported herein, but the higher the $P$ values are, the more uncertainty there is around these estimates. When outliers were included in the analysis, the difference between the lowest and highest participant groups was larger (\$52.66) and significantly different from zero $(P<0.001)$. As shown above, results were similar in sensitivity analyses that employed a random effects model as another option to avoid selection bias.

With reference to other research, results from the present study are consistent with research by Abraham and colleagues, who examined a program offered by the University of Minnesota that provided the same incentive (\$20/month) for at least 8 (vs 12 in the present study) monthly fitness center visits. ${ }^{20}$ In that study, annual health care spending for participants with the highest level of participation-9 to 12 fitness center visits per month-was $18 \%$ lower than for than nonparticipants. However, removal of high-cost outliers (approximately $1 \%$ of the sample) impacted results: although a similar trend for lower health care costs was evident, the estimate of health care savings at the highest level of participation was appreciably smaller and nonsignificant after excluding high-cost outliers. ${ }^{20}$

Two notable differences in methodology between the present study and the work by Abraham et al. ${ }^{20}$ warrant consideration. First, the present study compared health care costs only among FRP participants, with the low participation cohort serving as the comparator group, while the previous study compared costs of program participants to nonparticipants. The present study selected the lowest participation cohort, rather than nonparticipants, as the comparator to minimize differential motivation for modifying behavior among participants vs. nonparticipants. The lowest participation cohort did include a small number of health plan members $(2.3 \%)$ who signed up for FRP but had zero fitness center visits. These members were included in the low participation cohort because, unlike nonparticipants, they were motivated to enroll in FRP although they did not follow through. Second, in the present study the period for identifying high-cost outliers was also shorter and more contemporaneous: high-cost outliers were identified in the 6 months prior to FRP participation and during 6-12 months follow-up vs 3 years (including 2 years before the fitness program started and the 1-year follow-up period) in the previous study. ${ }^{20}$

Studies in elderly populations also have found evidence of an inverse dose response relationship between health care costs and increasing level of group physical activity participation. $^{25,26}$ Among managed care Medicare recipients who participated in a health plan-sponsored Silver Sneakers program, participants who averaged 2 or more visits per week incurred approximately $\$ 1000$ lower health care costs 
Table 5. Return on Investment Calculations

\begin{tabular}{|c|c|c|c|c|c|}
\hline & \multicolumn{4}{|c|}{$\begin{array}{c}\text { Level of Fitness Reimbursement } \\
\text { Program Participation }\end{array}$} & \multirow[b]{4}{*}{$\begin{array}{c}\text { Total } \\
\text { Sample }\end{array}$} \\
\hline & $\operatorname{Low}^{\mathrm{a}}$ & $\begin{array}{c}\text { Low- } \\
\text { Moderate }^{\mathrm{a}}\end{array}$ & $\begin{array}{c}\text { High- } \\
\text { Moderate }^{\mathrm{a}}\end{array}$ & $H i g h^{\mathrm{a}}$ & \\
\hline & $(\mathrm{n}=2779)$ & $(\mathrm{n}=2100)$ & $(\mathrm{n}=1914)$ & $(\mathrm{n}=1930)$ & \\
\hline & Mean (SD) & Mean (SD) & Mean (SD) & Mean (SD) & \\
\hline A. Months with $\geq 12$ visits, $\%$ & 1.74 & 15.63 & 46.72 & 86.38 & 33.68 \\
\hline $\begin{array}{l}\text { B. Mean monthly incentive payment, } \\
(\$ 20 \text { X Row A), \$ }\end{array}$ & 0.35 & $\$ 3.13$ & 9.34 & 17.28 & 6.74 \\
\hline C. Mean PMPM healthcare costs, $\$^{\mathrm{b}}$ & Reference Group & $(6.14)$ & $(16.40)$ & $(20.01)$ & $(9.50)$ \\
\hline D. Monthly net return (ie, -C-B) & $(0.35)$ & 3.01 & 7.06 & 2.73 & 2.77 \\
\hline E. Return on Investment Ratio (ie, -C/B) & Reference Group & 1.96 & 1.76 & 1.16 & 1.41 \\
\hline
\end{tabular}

${ }^{a}$ Participation cohorts defined according to number of PMPM fitness center visits during post-index period: low, $<4$; low-moderate, $\geq 4$ and $<8$; high-moderate, $\geq 8$ and, $<12$; high, $\geq 12$; outliers removed.

${ }^{\mathrm{b}}$ Row $\mathrm{C}$ reports the mean difference in health care expenditures PMPM for the group of interest vs. the low group.

${ }^{c}$ Row $\mathrm{E}$ reports the average dollars in health care expenditures that were saved or lost, per dollar spent on the incentive. Only the cost of the incentive is included in the return on investment analysis. See Discussion section regarding the perspectives for and limitations of the analysis.

PMPM, per member per month.

in the second year of the program than participants with less than 2 mean weekly visits. ${ }^{25}$ Cost savings of approximately $\$ 3700$ per year also were observed among older patients with diabetes who more regularly participated in a community exercise program sponsored by their health plan. ${ }^{26}$

With regard to the financial ROI in the incentive program, there are multiple perspectives to consider and some limitations worth noting. Perspectives include those of the vendor (Optum), the health plan client who purchased the program from Optum, and members of the health plan who used the fitness facilities. Each of these entities may bear some financial risk, so each may regard the ROI methods and results differently. From Optum's perspective the risk involved is related to whether it can offer the program at a price that exceeds the cost of the incentive and other production costs, and whether the program would yield enough savings for the health plan client to exceed these costs. That was indeed the case.

From the program sponsor's (ie, the health plan client's) perspective, the intervention was the $\$ 20$ payment it gave to individuals who visited a fitness center at least 12 times in any given month, plus other costs that influence the total price it paid Optum for the program. Prices are negotiated on a clientby-client basis, and vary depending on client size, locale, and whether the client chooses to pay for or spend their own resources on communications to promote the program (because such efforts are associated with higher use of the fitness facilities, which in turn yields more savings). Although the full price paid by the client for this study is not specified, the study does provide insight about whether ROI values would still be above 1.0 if those costs were included in the analysis.

Specifically, in the analysis that excluded outliers from the sample, the savings in health care expenditures were equal to $\$ 1.41$ per dollar spent on the incentive. The savings were much higher when analyses included the full sample. In that case the ROI ratio reflects a savings of $\$ 3.13$ per dollar spent on the incentives (ROI calculations for the full sample are available upon request). Depending on pricing variations for individual clients, ROI values based on analyses that exclude outliers may not exceed 1.0 for some clients, while for others ROI values may still exceed 1.0. However, for all of the clients Optum has done business with so far, ROI values would exceed 1.0 when the full price is accounted for, if savings estimates are based on the full sample, including outliers.

From the fitness facility users' perspective, participating in the fitness facility program was free, but the cost of the gym membership also might need to be accounted for in an ROI analysis. Gym membership costs would need to be included only if the incentive either motivated the user to buy a facility membership that she or he did not already have, or to extend a membership she or he was thinking of cancelling. The study team doubts either would occur very often. It seems more likely that the incentive would motivate those who already have a membership to exercise more without affecting gym membership costs. Unfortunately, data were not available to test this hypothesis.

Data also are lacking about fitness center utilization prior to the incentive program, and there are only limited data about whether the incentive program may have increased that utilization. The only data available about the potential impact of the incentive on fitness center utilization came from a subsequent satisfaction survey that was conducted among program participants. Among participants, $61.3 \%$ of the survey respondents agreed that their health improved since enrolling in the program and $95.6 \%$ of those respondents said an increase in exercise contributed to this improvement. Although these results may support the notion that the program influenced how much users exercised, they are inconclusive.

Finally, there may be additional savings beyond reduced health care expenditures to consider, such as those related to reduced absenteeism or improved productivity at work that are associated with exercising more. Data were not available 
to estimate productivity savings in this study, but it should be considered for future studies. Thus, ROI from the incentive feature cannot be reported with much certainty and the results should be considered in this context.

The results of this study add to the relatively small body of evidence suggesting lower health care costs with increasing level of participation in physical activity programs. ${ }^{19,20,25,26}$ Physical activity is a potentially modifiable risk factor for preventing many common chronic health conditions. Conservative estimates indicate that $24 \%$ of working age adults have 1 common chronic condition, and $18 \%$ have 2 or more common chronic conditions. ${ }^{27}$ Even modest reductions in chronic disease burden among employees may lead to large reductions in health care spending. ${ }^{28}$ Although this study's results coupled with previous research indicate that health care savings may be correlated with increasing participation in fitness activities, additional research is needed to extend these findings. Future studies should examine both clinical and economic outcomes. Also, variability in the intensity and duration of physical exertion corresponding to observed fitness activities should be accounted for and the sustainability of benefits over longer periods should be evaluated.

The results of this study are based on a retrospective analysis of administrative data and there are inherent limitations associated with this approach. Number of fitness center visits was used as a surrogate for level of physical activity; however, the frequency of fitness center visits does not provide information regarding the overall intensity or duration of physical activity, which has been linked to improved health outcomes. In the future, it would be useful to ask fitness center users to also use wearables such as FitBit or other technologies ${ }^{29,30}$ to gather hard data on the intensity of exercise.

Propensity score weighting and fixed and random effects models were used to mitigate socioeconomic and other differences in participant characteristics among cohorts, including pre-FRP enrollment health care costs and health risk scores. Although this approach was useful, data regarding frequency of pre-FRP fitness center visits was not available, nor is it known how many visits to the FRP would have been used by any sample member in the absence of the $\$ 20$ incentive, so it is possible that the health benefits achieved through regular pre-FRP fitness center visits (or other pre-FRP physical activity programs) carried over into study cohorts. For example, high frequency FRP users already may have been participating at a high level in a fitness center or other physical activity program prior to signing up for the FRP and, thus, could have entered the program as healthier individuals.

Next, the mean length of follow-up was just under 1 year. Longer term evaluations are needed to determine if the apparent health savings observed change over time. Finally, this study focused solely on the relationship between fitness facility use and medical expenditures. Data were lacking on associated decreases in absenteeism, increases in productivity at work, and reduced disability expenditures, if any. Others may wish to investigate these outcomes. The fitness center literature is mixed with respect to the relationship between physical activity and work productivity, and results often vary with study design, type of intervention, or population characteristics. ${ }^{31-33}$

\section{Conclusions}

Among participants in an employer-sponsored fitness program that included a financial incentive for regular fitness center visits, a trend for lower total health care costs was observed with more frequent fitness center visits. Compared with the lowest level of participation $(<4$ visits/ month) monthly savings in health care costs ranged from $\$ 6.14(2.6 \%)$ per participant at the low-moderate level of participation ( $\geq 4$ and $<8$ visits per month) to $\$ 20.01(8.4 \%)$ per participant at the highest level of participation $(\geq 12$ visits per month). When outliers (those with very high health care costs) were retained in the sample, significant differences in costs were found when comparing those in the high participation group to those in the low participation group. These results suggest a dose-response pattern to FPR program use that may help save health care expenditures. Because of data limitations, one should view the ROI analyses with caution, noting, however, that they seem to indicate savings in health care expenditures that exceed the cost of the incentive program, especially if all sample members are included in the analyses.

\section{Author Disclosure Statement}

Ms. Navratil-Stawn, Mr. Hartley, and Dr. Ozminkowski declared the following conflicts of interest with respect to the research, authorship, and/or publication of this article: the authors are employed by and own stock in UnitedHealth Group. Stock or other compensation did not influence the content of this paper.

The authors received the following financial support for this article: this research was supported by UnitedHealth Group, Minnetonka, Minnesota.

\section{Acknowledgments}

The views expressed in this manuscript are the authors' and do not necessarily represent the views of Optum or UnitedHealth Group.

Sarah Peirce-Sandner, MS, and Virginia Rosen (Optum, Eden Prairie, Minnesota) provided medical writing support for this manuscript.

\section{Prior Presentations}

This article was presented at the Population Health Alliance Forum, December 2014, Scottsdale, Arizona.

\section{References}

1. Lee IM, Shiroma EJ, Lobelo F, et al. Effect of physical inactivity on major non-communicable diseases worldwide: an analysis of burden of disease and life expectancy. Lancet. 2012;380:219-229.

2. Sattelmair J, Pertman J, Ding EL, Kohl HW 3rd, Haskell W, Lee IM. Dose response between physical activity and risk of coronary heart disease: a meta-analysis. Circulation. 2011;124:789-795.

3. Jeon CY, Lokken RP, Hu FB, van Dam RM. Physical activity of moderate intensity and risk of type 2 diabetes: a systematic review. Diabetes Care. 2007;30:744-752.

4. Lee IM, Paffenbarger RS Jr. Physical activity and stroke incidence: the Harvard alumni health study. Stroke. 1998;29: 2049-2054. 
5. Friedenreich CM. Physical activity and breast cancer: review of the epidemiologic evidence and biologic mechanisms. Recent Results Cancer Res. 2011;188:125-139.

6. Wolin KY, Yan Y, Colditz GA, Lee IM. Physical activity and colon cancer prevention: a meta-analysis. $\underline{\mathrm{Br} \mathrm{J} \text { Cancer. }}$ 2009;100:611-616.

7. Office of Disease Prevention and Health Promotion. 2008 Physical Actvitiy Guidelines for Americans. http://www.health .gov/paguidelines/guidelines/. Accessed March 12, 2015.

8. Schiller JS, Lucas JW, Peregoy JA. Summary health statistics for U.S. adults: national health interview survey, 2011. Vital Health Stat. 2012;10(256):1-218.

9. US Burden of Disease Collaborators. The state of US health, 1990-2010: burden of diseases, injuries, and risk factors. JAMA. 2013;310:591-608.

10. Pratt M, Macera CA, Wang G. Higher direct medical costs associated with physical inactivity. Phys Sportsmed. 2000; 28:63-70.

11. Rubin BK. Mucus, phlegm, and sputum in cystic fibrosis. Respir Care. 2009;54:726-732.

12. Henke RM, Goetzel RZ, McHugh J, Isaac F. Recent experience in health promotion at Johnson \& Johnson: lower health spending, strong return on investment. Health Aff (Millwood). 2011;30:490-499.

13. Hochart $C$, Lang M. Impact of a comprehensive worksite wellness program on health risk, utilization, and health care costs. Popul Health Manag. 2011;14:111-116.

14. Naydeck BL, Pearson JA, Ozminkowski RJ, Day BT, Goetzel RZ. The impact of the Highmark employee wellness programs on 4-year healthcare costs. J Occup Environ Med. 2008;50:146-156.

15. Ozminkowski RJ, Ling D, Goetzel RZ, et al. Long-term impact of Johnson \& Johnson's health \& wellness program on health care utilization and expenditures. J Occup Environ Med. 2002;44:21-29.

16. Baicker K, Cutler D, Song Z. Workplace wellness programs can generate savings. Health Aff (Millwood). 2010; 29:304-311.

17. Caloyeras JP, Liu H, Exum E, Broderick M, Mattke S. Managing manifest diseases, but not health risks, saved PepsiCo money over seven years. Health Aff (Millwood). 2014;33:124-131.

18. Nyman JA, Abraham JM, Jeffery MM, Barleen NA. The effectiveness of a health promotion program after 3 years: evidence from the University of Minnesota. Med Care. 2012;50:772-778.

19. Lu C, Schultz AB, Sill S, Petersen R, Young JM, Edington DW. Effects of an incentive-based online physical activity intervention on health care costs. J Occup Environ Med. 2008;50:1209-1215.

20. Abraham JM, Nyman JA, Feldman R, Barleen N. The effect of participation in a fitness rewards program on medical care expenditures in an employee population. J Occup Environ Med. 2012;54:280-285.

21. Charlson ME, Pompei P, Ales KL, MacKenzie CR. A new method of classifying prognostic comorbidity in longitu- dinal studies: development and validation. J Chronic Dis. 1987;40:373-383.

22. Wennberg JE, Fisher ES, Skinner JS. Geography and the debate over Medicare reform. Health Aff (Millwood). 2002;Suppl Web Exclusives:W96-114.

23. Curtis LH, Hammill BG, Eisenstein EL, Kramer JM, Anstrom KJ. Using inverse probability-weighted estimators in comparative effectiveness analyses with observational databases. Med Care. 2007;45(10 suppl 2): S103-S107.

24. Mansson R, Joffe MM, Sun W, Hennessy S. On the estimation and use of propensity scores in case-control and case-cohort studies. Am J Epidemiol. 2007;166: 332-339.

25. Nguyen HQ, Ackermann RT, Berke EM, et al. Impact of a managed-Medicare physical activity benefit on health care utilization and costs in older adults with diabetes. Diabetes Care. 2007;30:43-48.

26. Nguyen HQ, Ackermann RT, Maciejewski M, et al. ManagedMedicare health club benefit and reduced health care costs among older adults. Prev Chronic Dis. 2008;5(1):A14.

27. Ward BW, Schiller JS, Goodman RA. Multiple chronic conditions among US adults: a 2012 update. Prev. Chronic Dis. 2014;11:E62.

28. Milani RV, Lavie CJ. Impact of worksite wellness intervention on cardiac risk factors and one-year health care costs. Am J Cardiol. 2009;104:1389-1392.

29. Cadmus-Bertram LA, Marcus BH, Patterson RE, Parker BA, Morey BL. Randomized trial of a Fitbit-based physical activity intervention for women. Am J Prev Med. 2015;49: 414-418.

30. Ferguson T, Rowlands AV, Olds T, Maher C. The validity of consumer-level, activity monitors in healthy adults worn in free-living conditions: a cross-sectional study. Int J Behav Nutr Phys Act. 2015;12:42.

31. Cancelliere C, Cassidy JD, Ammendolia C, Cote P. Are workplace health promotion programs effective at improving presenteeism in workers? A systematic review and best evidence synthesis of the literature. BMC Public Health. 2011;11:395.

32. Pereira MJ, Coombes BK, Comans TA, Johnston V. The impact of onsite workplace health-enhancing physical activity interventions on worker productivity: a systematic review. Occup Environ Med. 2015;72:401-412.

33. Rongen A, Robroek SJ, van Lenthe FJ, Burdorf A. Workplace health promotion: a meta-analysis of effectiveness. Am J Prev Med. 2013;44:406-415.

Address correspondence to: Ms. Jessica Navratil-Strawn Optum

P.O. Box 9472

Minneapolis, MN 55440-9472

E-mail: jessica.navratil-strawn@optum.com 